\title{
Effective Moment of Inertia of Beam-Slab Section under Lateral Load
}

\author{
Yasir W. Abduljaleel ${ }^{1}$, Mustafa M. Khattab ${ }^{2}$, Adnan Falih Ali ${ }^{3}$ \\ ${ }^{1}$ College of Engineering, Aliraqia University, \\ Baghdad, Iraq \\ yasir.wisam@aliraqia.edu.iq; 40310@uotechnology.edu.iq \\ ${ }^{2}$ Civil Engineering Department, University of Technology, \\ Baghdad, Iraq \\ ${ }^{3}$ College of Engineering, University of Baghdad, \\ Baghdad, Iraq \\ af_bas1@yahoo.com
}

\begin{abstract}
This study developed the modified equivalent frame method, using column elements and equivalent slab-beam elements for two-way slab systems under lateral loads. A detailed comparative study between the F.E analysis, which is based on the three dimensional full width of slab, and 3D frame analysis using different types of effective moment of inertia of beam-slab section. The purpose of this step is to choose an appropriate model of effective width of slab to represent the full width of slab under lateral loads. The dynamic analysis was done using finite element procedure provided by ETABS. Parametric studies were carried out to evaluate the effects of several factors such as panel of slab aspect ratio, column aspect ratio, column to span ratio, irregularity in plan of buildings and height of buildings. Two heights of buildings were considered for those above mentioned factors, these are (45m and $75 \mathrm{~m})$. This study presents the modified beam model, which gives the effective moment inertia of slab-beam system under lateral load. The response of the proposed model gives a good result in comparison with F.E idealization with small error range from (2-5) $\%$ for displacement and frequency and (5-8) \% for base shear and base moment
\end{abstract}

Keywords: Two-way slab, Moment of Inertia of Beam-Slab Section, Lateral Load.

\section{Introduction}

The Equivalent Frame Method is a widely used procedure for the analysis of reinforced concrete buildings. When formulated in the 1960's, the method represented a significant contribution to the analysis of monolithic reinforced concrete buildings. Recently, the method has been increasingly criticized by researchers and professional engineers. Typical of these criticisms are:

- The method contains some irrational rules such as the equivalent column

- It is too complex for the accuracy achieved in predicting the response of the building

- The method was devised only for the analysis of single story frames with gravity loads and there is no indication that it is appropriate for laterally loaded frames.

The load-transfer mechanism under gravity loads is different from that under lateral loads. When two-way slab systems are subjected to lateral loading, columns displace first, and the forces in columns are transferred to the torsional elements. Subsequently, the torsional elements transfer the forces to the slabs. Thus, under lateral loads, the flexural deformation of columns is restrained by both the stiffness of torsional elements and the flexural stiffness of the slab; it is more appropriate to use equivalent slab elements under lateral loads rather than to use equivalent column elements. It is noted that, under gravity loads, slabs transfer the forces to the torsional elements first, and then the forces of the torsional elements are transferred to the columns. The Modified Equivalent Frame Method (MEFM) for two-way slab systems under lateral loads consist of equivalent slab elements and column elements instead of the equivalent column elements and slab elements used in the ACI-EFM.

It is useful to start with a quote from Vanderbilt. Who was writing about an unbraced flat plate structure: "Its analysis presents a number of interesting problems, most of which center on the proper way to consider the behavior of the planar slabs". The two-way slab with substantial beams on all column lines will respond as a beam-and-column frame, with little participation from the slabs since most of the stiffness will be concentrated in the beams. Questions about states of cracking will remain important if drift is to be predicted properly, but the problems are less crucial than those in beamless slabs. 
This conclusion has not changed in the last two decades. Vanderbilt went on to compare the results of analyses that were extensions of the equivalent frame method to the lateral load case (with the torsional members present). His equivalent frame method (a program called EFRAME) had cases in which the torsional members acted with the columns (equivalent columns) and cases in which they acted with the beams (equivalent beams). These two approaches produced nearly the same reasonable results. Comparisons with the deflected shapes of a nearly untracked eight-story model slab structure under various lateral loadings are quite favorable.

The second approach that Vanderbilt considered is the use of a reduced section rigidity (EI) of the slab elements, based on an effective-width concept (which is defined as the width of a slab that provides the same column displacement as the true slab, if a uniform rotation is assumed across slab width). In this frame, the columns have (EI) of the columns, with no reduction to account for the torsional members. Effective widths had been determined earlier by several investigators, each study considered uncrackcd elastic slabs.

Pecknold, 1975, conducted one of the earliest analytical studies on elastic modeling of flat slabs. The simplified version of Pecknold's formula for computing the effective slab with ratio, $\alpha$, is

$$
\alpha_{i}=\frac{1.02\left(\frac{C_{1}}{C_{2}}\right)}{0.05+0.002\left(\frac{l_{1}}{l_{2}}\right)^{4}-2\left(\frac{c_{1}}{l_{1}}\right)^{3}-2.8\left(\frac{c_{1}}{l_{1}}\right)^{2}+1.1\left(\frac{c_{1}}{l_{1}}\right)}
$$

The expression is valid for $\left(0.5 \leq\left(\mathrm{c}_{1} / \mathrm{c}_{2}\right) \leq 2.0\right.$ and $\left(0.5 \leq\left(l_{1} / l_{2}\right) \leq 2.0\right)$.

Luo and Durrani also suggested that the effect of cracking in slabs may be included in the models reasonably well by using the ACI code equation 9-7 (ACI 318-95) for the effective moment of inertia, $\left(\mathrm{I}_{\mathrm{e}}\right)$.

Grossman, 1997, concluded that the flat slab system has a good resistance capacity for the lateral loads as well as gravity loads provided a proper detailing in owas proposed by Grossman as shown in Eq. (3) by modifying the previous procedures for the equivalent frame method.

$$
\alpha l_{2}=\mathrm{KD}\left[0.3 l_{1}+\mathrm{C} 1\left(l_{2} / l_{1}\right)+\left(\mathrm{C}_{2}-\mathrm{C}_{1}\right) / 2\right] \times(\mathrm{d} / 0.9 \mathrm{~h})(\mathrm{KFP})
$$

With limits: (0.2) (KD) (KFP) $l_{2} \leq \alpha l_{2} \leq(0.5)(\mathrm{KD})(\mathrm{KFP}) l_{2}$

$\mathrm{KFP}=$ factor adjusting $\boldsymbol{\alpha} \boldsymbol{l}_{2}$ at edge, exterior and corner supports (1.0 for interior supports, 0.8 for exterior and edge supports, 0.6 for corner supports).

In case of exterior columns, adjustments are made by multiplying the effective width $\left(\boldsymbol{\alpha} \boldsymbol{l}_{2}\right)$ by $\left[\boldsymbol{l}_{\mathbf{3}}+\left(\boldsymbol{l}_{\mathbf{2}} / \mathbf{2}\right)\right] / \boldsymbol{l}_{\mathbf{2}}$

Kim and Lee, 2005, developed a method which employs super elements using the matrix condensation technique and fictitious beams are used in the development of super elements to enforce the compatibility at the interfaces of super elements. In that study, the stiffness degradation due to cracking in a flat slab system considered in the equivalent frame method was taken into account by reducing the modulus of elasticity of floor slabs based on linear elastic finite element analysis. Static and dynamic analyses of example structures were performed and the efficiency and accuracy of the proposed method were verified by comparing the results with those of the refined finite element model and the equivalent frame method.

\section{Methodology}

\section{1. Standards and Simple Model for Buildings:}

A widely adopted model for buildings, which is usually able to adequately represent the distribution of stiffness, is the three dimensional frame with rigid floor diaphragms, such that:

a) Beams and columns of the building are modeled as one dimensional member, mutually connected at points named nodes.

b) It is assumed that all the columns in a building are connected by floor diaphragms that are rigid in their own plane; therefore, every floor has only two translational and one rotational degree of freedom.

c) Nonstructural elements, as partition walls, are usually not included in the model.

d) Fixed base: The columns of a building are assumed to be fixed at their base to rigid foundation (no soil-structure interaction effect is considered in this study).

e) One directional earthquake input: Only one direction of response values is applied at the junction of columns and floor diaphragms; due to the fixed base assumption, all supports are assumed to move in phase (no vertical translation is applied to the buildings). 
f) Lumped mass at floor level: The mass and mass rotational moments of inertia of a building are assumed to be lumped at the floor levels.

g) Damping is assumed to be viscous, and the damping ratio $\zeta(5 \%)$ is constant throughout the dynamic seismic loading and unloading of the structure.

h) Considering members with rigid ends simulates the behavior of beam-column joins.

For building containing slab-beam system, the effective slab width concept is not readily useable and a more general method is required. The equivalent slab width is defined as the width of a slab provides the same column displacement as true slab. Depending on this principle, a comparative study between the two types of idealization (slab analysis and frame analysis) is presented in order to choose an appropriate model of effective width of slab to represent the full width of slab under lateral loads.

\section{2. Slab Analysis Idealization [Allen and Darvall, 1977]}

Figure 1A. Shows, schematically, the separation of a beam-slab floor into plate and beam elements. The stiffness matrices of the plate elements allow for plate bending and for membrane actions due to the slab being connected to the beam elements above their centroids. Plate elements adjacent to the beam elements have their stiffnesses transformed across the half-width of the beams. The standard stiffnesses of the beam elements require two forms of transformation:

(1) Rotation and translation from their local axes to the global axes; and

(2) A reduction in the degrees of freedom at each end from six to five, this is due to the inability of the floor panel to rotate about a vertical axis. With all element stiffnesses expressed in terms of compatible degrees of freedom in the global system, the assembly of the gross stiffness matrix for a panel or group of panels proceeds in the conventional manner. The gross stiffness matrix accurately models the flexural and torsional characteristics of the floor, assuming the floor to have linear elastic behavior.

\section{3. Frame Analysis Idealization}

A multistory building (slab-beam system) is analyzed as 3D frame model by using space frame element for beam and column but the effect of slab is considered as effective flange width of beam. The effective width of a flange procedure can be summarized below.

\section{3. 1. Procedure by Fraser}

Fraser, 1982, adopted simple rules for evaluation of the stiffness of equivalent beam under lateral loads as show in Figure 2.B.

$$
\begin{gathered}
\mathrm{I}_{\mathrm{b}}=\frac{\mathrm{b}_{\mathrm{w}} \mathrm{D}^{3}}{12} \\
\mathrm{R}_{\mathrm{b}}=\frac{\text { slab rigidity }}{\text { flexture stiffness of beam stem }} \\
\mathrm{R}_{\mathrm{b}}=\frac{\mathrm{Eh}^{3}}{12\left(1-\mathrm{v}^{2}\right)} * \frac{12 \mathrm{l}_{1}}{\mathrm{E}_{\mathrm{w}} \mathrm{D}^{3}} \\
\mathrm{R}_{\mathrm{b}}=\frac{l_{1}}{b_{w}} *\left(\frac{t_{f}}{D}\right)^{3}
\end{gathered}
$$

where,

$v=0.15$ for concrete

$\mathbf{I}_{\mathbf{b}}$ for in plane beam stem

For interior beam

$$
\begin{array}{lll}
K_{e}=4+32 R_{b} & \text { for } & R_{b} \leq 0.1 \\
K_{e}=7+1.6 R_{b} & \text { for } & R_{b}>0.1
\end{array}
$$

For edge beams

$$
\begin{array}{rll}
\mathrm{K}_{\mathrm{e}}=4+18 \mathrm{R}_{\mathrm{b}} & \text { for } & \mathrm{R}_{\mathrm{b}} \leq 0.1 \\
\mathrm{~K}_{\mathrm{e}}=5.75+\mathrm{R}_{\mathrm{b}} & \text { for } & \mathrm{R}_{\mathrm{b}}>0.1 \\
\mathrm{I}_{\mathrm{e}}=\frac{K_{e}}{6} I_{b} &
\end{array}
$$


$\mathbf{I}_{\mathbf{e}}=$ effective moment of inertia of a beam -slab section under lateral load

\section{3. 2. Procedure by Habeeb}

Habeeb, 2007, developed models based on full width of a slab section and reduce moment of inertia of beam -slab section as show in Figure 2.C.

$$
\mathrm{Ie}=0.275 \mathrm{Ig}
$$

where,

$\mathrm{I}_{\mathrm{g}}=$ the moment of inertia of full beam slab section

\section{4. Proposed procedure}

The proposed model was conducted based on Vanderbilt studies in 1981 that give a range for expected member's stiffness without specifying constant value. In the present study, it is observed

- When the member stiffness is evaluated based on $\left(\mathrm{I}_{\mathrm{e}}=0.275 \mathrm{Ig}_{\mathrm{g}}\right)$ as Habeeb suggested, it was observed that model is most appropriate model for representing building in base shear and base moment, but this model has large error (compared with that of F.E.M) in representing frequency and displacement.

-When the member stiffness is evaluated based on ( $\mathrm{I}_{\mathrm{e}}$ approximately equal to $0.5 \mathrm{I}_{\mathrm{g}}$ ) as Fraser suggested, it was observed that model is most appropriate model for representing building in displacement and frequency, but this model has large error (compared with that of F.E.M) in representing base shear and base moment.

Based on that and as expected, evaluating of member stiffness based on the above value of $\left(\mathrm{I}_{\mathrm{e}}\right)$. The equation is modified to get minor differences compared with that of F.E.M as follow: -

$$
\mathrm{Ie}=0.425 \mathrm{Ig}
$$

The proposed procedure is an appropriate model for representing buildings in (displacement, frequency, base shear and base moment) with acceptable differences.

\section{5. Mass of a beam -slab section}

Stiffness matrices of the 2-D beam element are evaluated on the basis of the above expressions for moment of inertia. For earthquake load evaluation, it is important that the mass values and hence mass matrices need to be evaluated. Mass matrices of $2 \mathrm{D}$ beam element are evaluated on the basis of the full slab-beam width that is bounded by the center lines of adjacent frames. This means that the mass values of each of the interior and edge beams are based on the gross area of the corresponding section.

Generally, (for two and three dimensional frames) the mass of a structure is mainly distributed at the floor levels. This distribution permits the treatment of all masses of the structure as lumped at the floor level in calculating the mode shapes that are essential in the response spectrum analysis. It is clear that there is no modification to the 2D beam slab mass, since the main reason for modifying the stiffness of $2 \mathrm{D}$ beam element is that using the stiffness value of an actual combined beam-full slab width might result in high overestimated stiffness values of a plane frame, and hence a stiffer plane frame. The mass model of typical interior slab-beam units is shown in Figure 1.

According to ASCE 10 (12.7.2), the effective seismic weight, W, of a structure shall include the total dead load and other loads listed below:

- In areas used for storage, a minimum of 25 percent of the floor live load (floor live load in public garages and open parking structures need not be included).

- Where provision for partitions is required by Section 4.2.2 in the floor load design, the actual partition weight or a minimum weight of $10 \mathrm{Psf}(0.48 \mathrm{kN} / \mathrm{m} 2)$ of floor area, whichever is greater.

- Total operating weight of permanent equipment.

- Where the flat roof snow load, Pf, exceeds $30 \mathrm{psf}(1.44 \mathrm{kN} / \mathrm{m} 2), 20$ percent of the uniform design snow load, regardless of actual roof slope. 
All load transferred to beam according to the equations below:

$$
\begin{gathered}
\text { Load on long beam }=\frac{W S}{3}\left(\frac{3-m^{2}}{2}\right) \\
\text { Load on short beam }=\frac{W S}{3}
\end{gathered}
$$

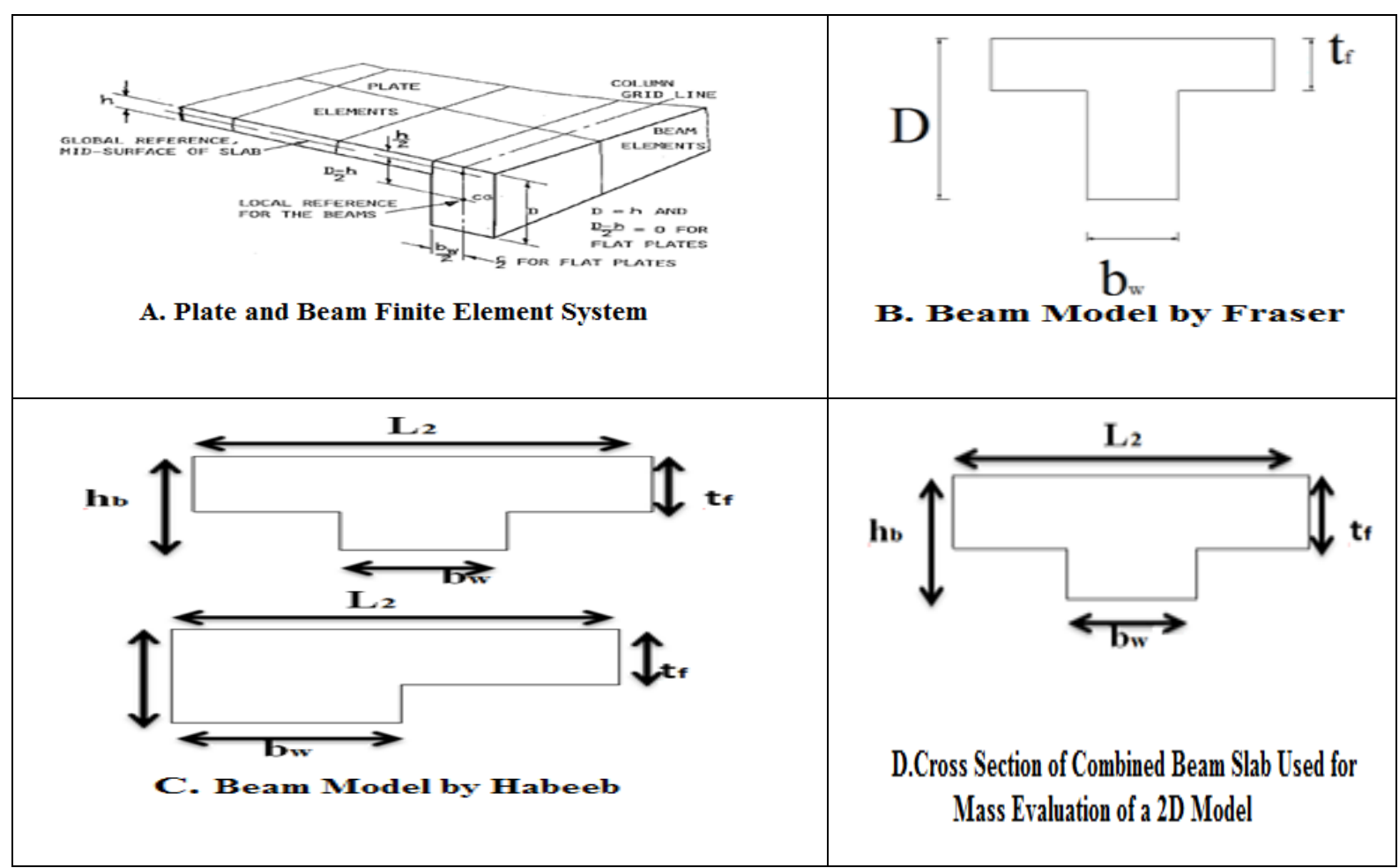

Fig. 1: Different Beam Idealization.

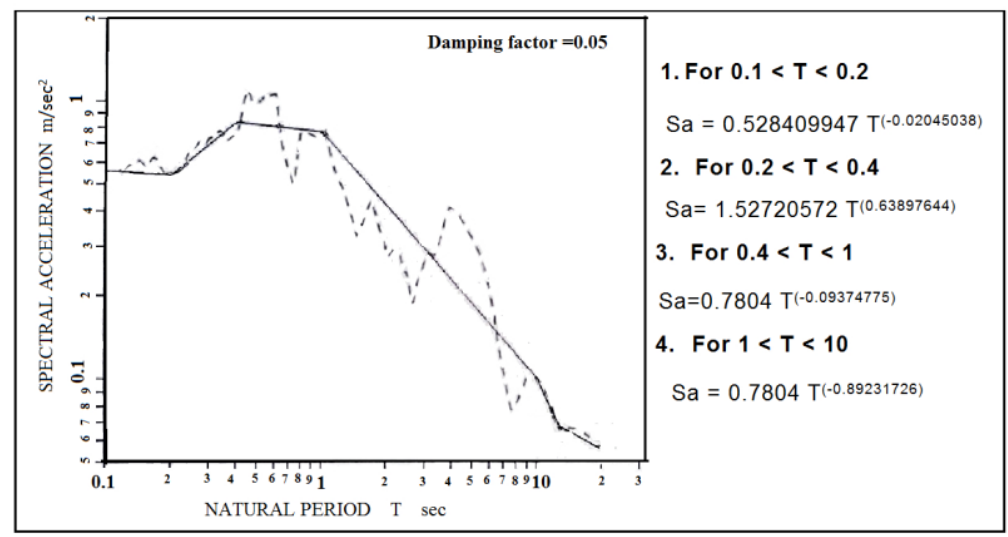

Fig. 2: Design Acceleration Response Spectrum.

\section{Parametric Studies}

The parameters affecting the moment of inertia of beam slab section under lateral load can be divided into geometries $\left(l_{2} / l_{1}, \mathrm{c}_{1} / l_{1}, \mathrm{c}_{2} / \mathrm{c}_{1}\right.$ and regularity in plan of building), gravity load and_material properties ( crack, creep and Poisson's ratio). The geometric parameters are only considered in this study.

For each parameter, analysis is performed through calculating the effective moment of inertia of beam slab section using different types of idealization (Fraser, Habeeb and proposed) and comparing the result with exact solution using F.E.M 


\section{1. Buildings with Complete Regularity}

In a symmetric building, all the lateral load-resisting elements at different locations in plan experience the same lateral displacement when subjected to unidirectional ground motion excitation. As a result, the force induced in each element is proportional to its lateral stiffness. This observation leads to a guideline that calls for assigning the design strength of the lateral load-resisting elements according to their stiffness.

\section{1. 1. Effects of slab aspect ratio $\left(I_{2} / I_{1}\right)$}

Three different types of slab panels $\left(l_{1} \times l_{2}\right)$ which are $(4 \mathrm{~m} \times 3 \mathrm{~m}, 4 \mathrm{~m} \times 4 \mathrm{~m}$ and $4 \mathrm{~m} \mathrm{X} 6 \mathrm{~m})$. These types of slab panels are investigated with:

- Fixed column section $(0.4 \mathrm{~m} \times 0.4 \mathrm{~m})$ and the ratio of $\mathrm{c}_{1} / l_{l}$ equals to 0.1 for 15 -story building

- Fixed column section $(0.5 \mathrm{~m} \mathrm{X} 0.5 \mathrm{~m})$ and the ratio of $\mathrm{c}_{1} / l_{l}$ equals to 0.15 for 25 -story building

The plan of used building shown in Figure 3. The effects of slab aspect ratio is less important than other parameter on the difference in response of building between F.E and frame analysis as shown in Figure 6 for 15 story building and in Figure 7 for 25 story building

\section{1. 2. Effects of column aspect ratio $\left(c_{2} / \mathbf{c}_{1}\right)$}

Five different types of column aspect ratio $c_{2} / c_{1}$ (e.g. 0.6, 0.8, 1, 1.2, and 1.4) are investigated. This type of aspect ratio is investigated with fixed slab panels $(4 \mathrm{~m} \mathrm{X} 4 \mathrm{~m})$ and the ratio of $c_{1} / l_{l}$ equals to 0.1 for 15 -story building and equals to 0.15 for 25 -story building. The plan of used building shown in Figure 3B. The difference in response of building, due to difference value of column aspect ratio, between F.E and frame analysis are shown in Figure 8 for 15 story building and in Figure 9 for 25 story building.
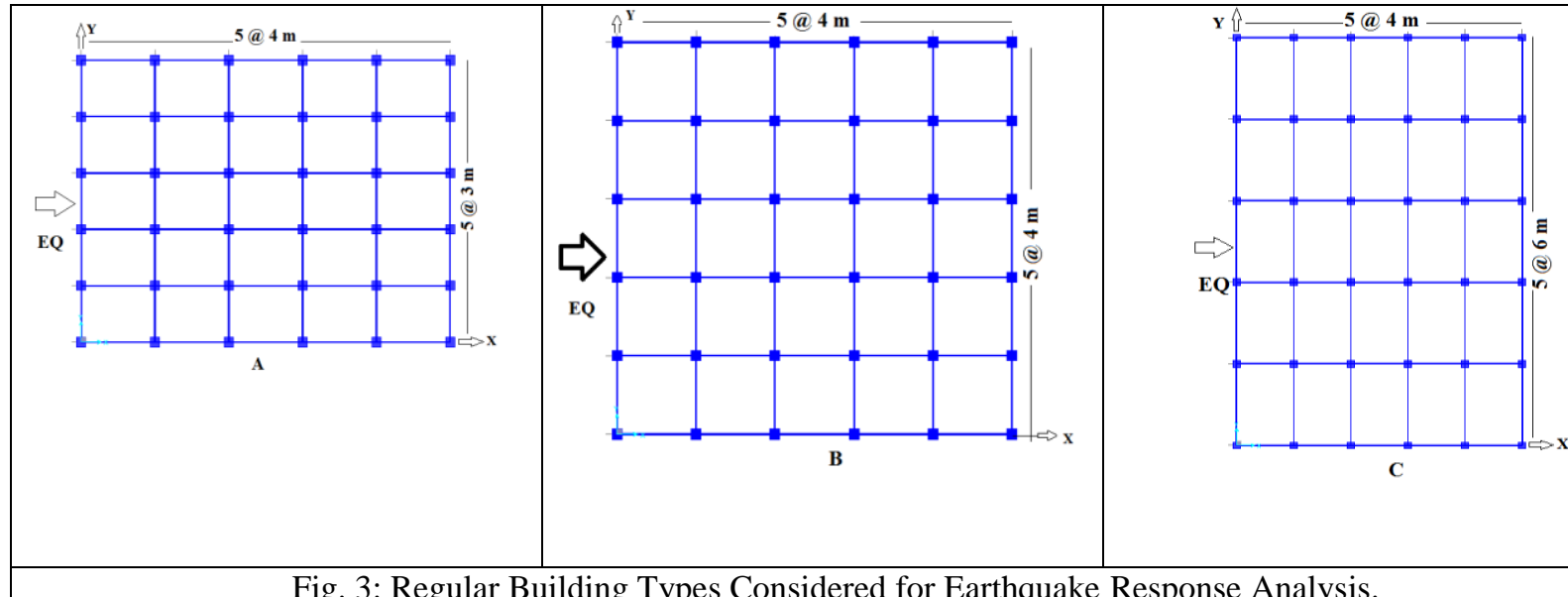

Fig. 3: Regular Building Types Considered for Earthquake Response Analysis.
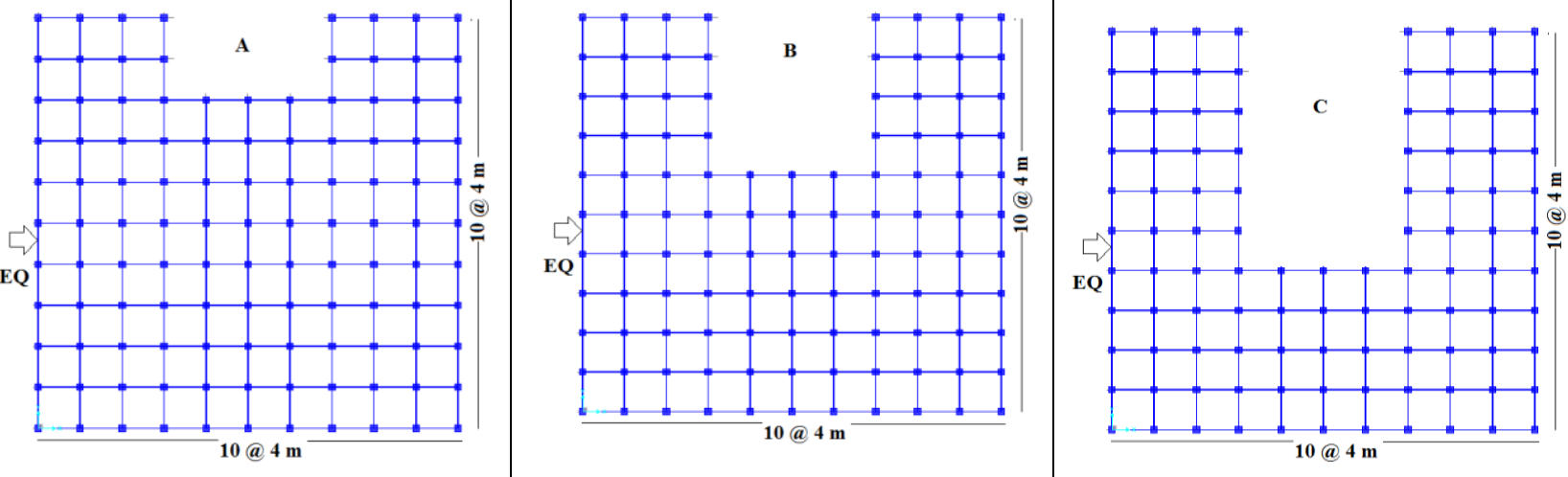

Fig. 4: Plan Configurations of Buildings with Different Irregularities. 


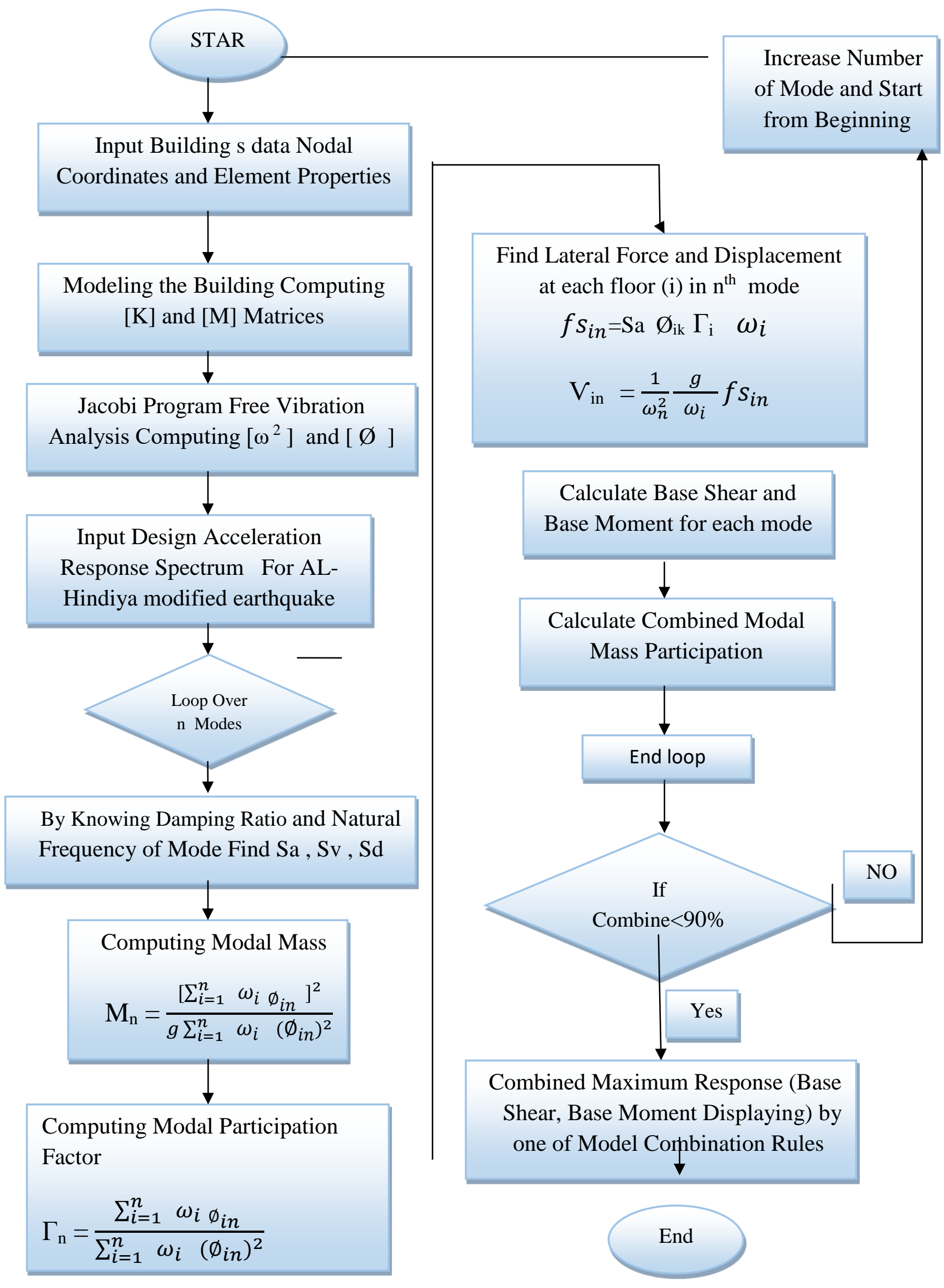

Fig. 5: Flow Chart of Response Spectrum Analysis. 


\section{1. 3. Effects of column to span ratio $\left(c_{1} / I_{1}\right)$}

Four different types of ratio $\mathbf{c}_{1} / l_{1}$ (e.g. $0.1,0.15,0.2$, and 0.25 ) are investigated. These ratios of $\mathbf{c}_{1} / l_{1}$ are investigated with fixed slab panel $(4 \mathrm{~m} \mathrm{X} 4 \mathrm{~m})$ and fixed column section $\left(c_{1}=c_{2}\right)$. The plan of used building shown in Figure 3B. In considering the effect of $\mathbf{c}_{1} / l_{l}$, the differences in response of building between $\mathbf{F} . \mathbf{E}$ and frame analysis are increased by increasing the ratio of $\mathbf{c}_{1} / l_{1}$ as shown in Figure $\mathbf{1 0}$ for 15 story building and in Figure $\mathbf{1 1}$ for 25 story building.

For figures mentioned above, the following note can be drawn on the responses of regular buildings irrespective to what types of parameters are: -

- The differences between all methods of beam of idealization approaches (except that of Habeeb ) become smaller as compared to the finite element, all of which result in overestimation of frequency except the method developed in the present work which results in a minor over estimation of displacements (in the range of $2 \%$ to $5 \%$ ).

- The method proposed by Frazer was found to result in the largest errors in the base moments as compared to F.E, while the method proposed in the present work results in the smallest base and story moments with differences against the F.E ranging from 5\% to $8 \%$ for medium to high rise buildings.

- The differences between all methods of beam of idealization approaches (except that of Habeeb) become smaller as compared to the finite element, all of which result in underestimation of displacement magnitudes except the method developed in the present work which results in minor over estimation of displacements (in the range of $2.5 \%)$.

- All methods of beam idealization result in over estimation of story shear as compared to the F.E (except that of Habeeb). The maximum difference of base shear ranges between $10 \%$ to $25 \%$ (differences increase as the building becomes higher). However, the procedure developed in the present work seems to result in accepted differences of story shear (in the range of $5 \%$ to $8 \%$ ).

\section{2. Effects of Floor Irregularity}

In an asymmetric building the location of the lateral load-resisting element affects the share of load that it should resist because the loadings on the rigid floors of these buildings are accompanied by torques caused by the structural eccentricity of the building. The force induced in each element from the floor torques is proportional to its contribution to the torsional stiffness of the building. The torque-induced force in an element is called the torsional shear. The location of an element not only determines the magnitude, but also the direction of the torsional shear. Depending on the direction of the torque, the torsional shear should be added to or subtracted from the forces induced in that element by the translational displacement of the floors.

Irregularities may result either from the presence of non-identical loads (dead or live) acting on the floor or from the asymmetry of building plan resulting in one or no axis of symmetry, and hence in an offset between the center of mass and the shear center of the floor under consideration.

It is known that section properties (lateral stiffness, axial stiffness, bending and torsional stiffness) are to be defined at the shear center of a building while the lateral forces due to an earthquake are to act through the center of mass.

Such an offset causes coupling of the lateral response to torsional response. Such a tendency results in different magnitudes of base shear of equivalent frames according to their distances from the center of mass.

To provide a better understanding of what is described above, two buildings of different plan configurations are considered, and these buildings are 25 and 15 stories. The building plans were considered such that each of them is $40 \mathrm{mx} 40 \mathrm{~m}$ but with different eccentricities (different offsets between the shear center and center of mass) as shown in Figure 4

Plots of both displacement (translation and rotation) and force (story shears and moments) responses are shown in Figure 11 for the 15- story buildings having limited, medium and large irregularities, respectively..

Detailed inspection of the responses presented in the above-mentioned figures reveals the following notes: -

a. For high rise buildings

- As far as the coupled translational response is concerned, all models (except that of Habeeb) give reasonable results (with difference of less than 6\%) as compared to that of the F.E. solution. Habeeb approach results in an error exceeding $20 \%$ in comparison with F.E. solution

- When considering the rotational response, all models deviate from the F.E. solution by magnitudes ranging from (6\% to $11 \%)$ 
- When the story shears and moments are considered, it is concluded that good predication of the responses are obtained based on the model adopted by Habeeb, (errors almost vanish), while other approaches result in errors ranging from $10 \%$ to $17 \%$ (in comparison with F.E model), however, the proposed model presented in the current work results in errors less than or equal to $10 \%$ as compared to the F.E.

b. For moderate-rise buildings (15-story).

- As far as the coupled translational response is concerned, all models (except that of Habeeb) give reasonable results (with difference of less than 3\%) as compared to the F.E. solution. Habeeb approach results in an error exceeding $17 \%$ in comparison with F.E. solution.

- When considering the rotational response, all models deviate from the F.E. solution by magnitudes ranging from (5\% to $8 \%)$
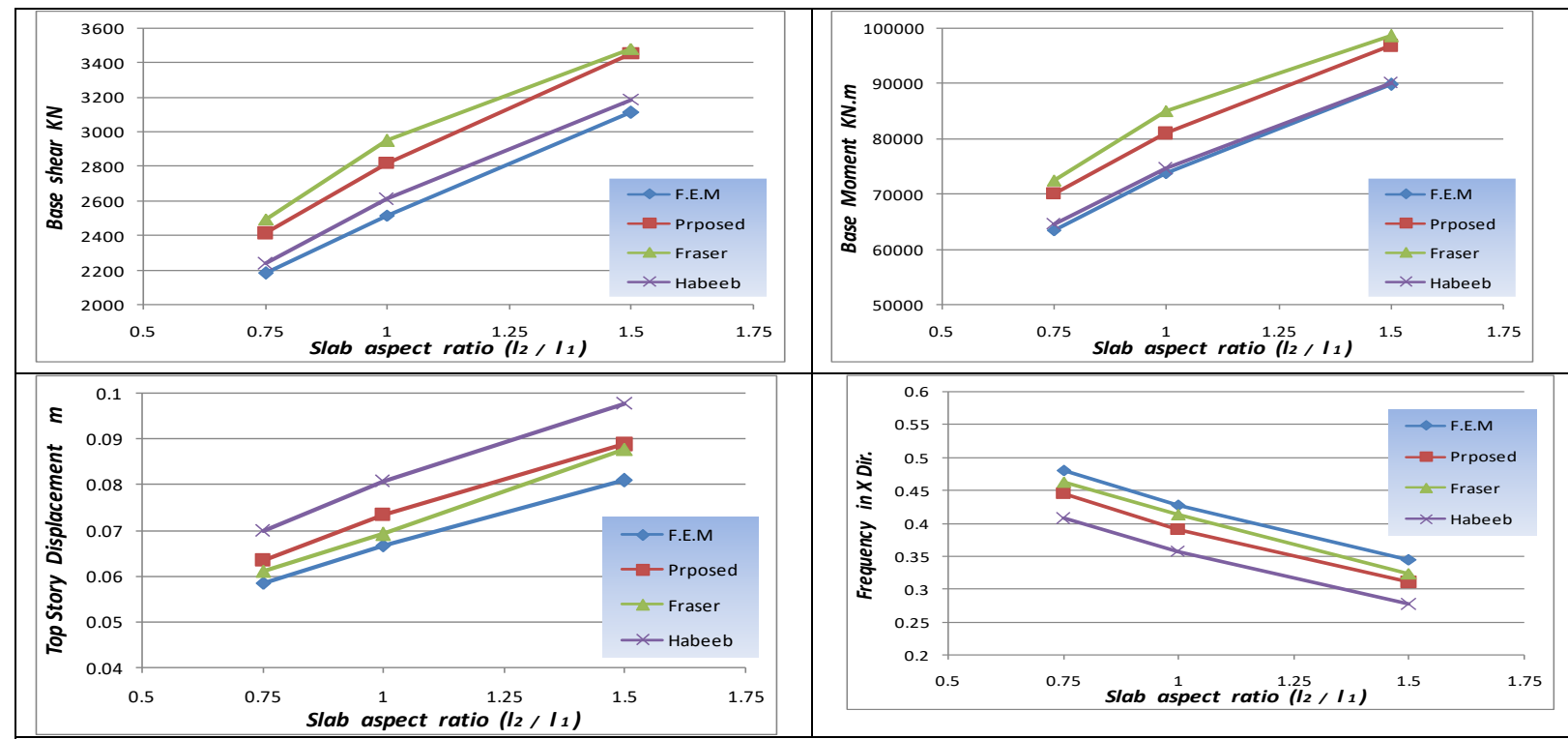

Fig. 6: Effects of Slab Aspect Ratio on Response of a 15-Story Building using Different Beams Models.
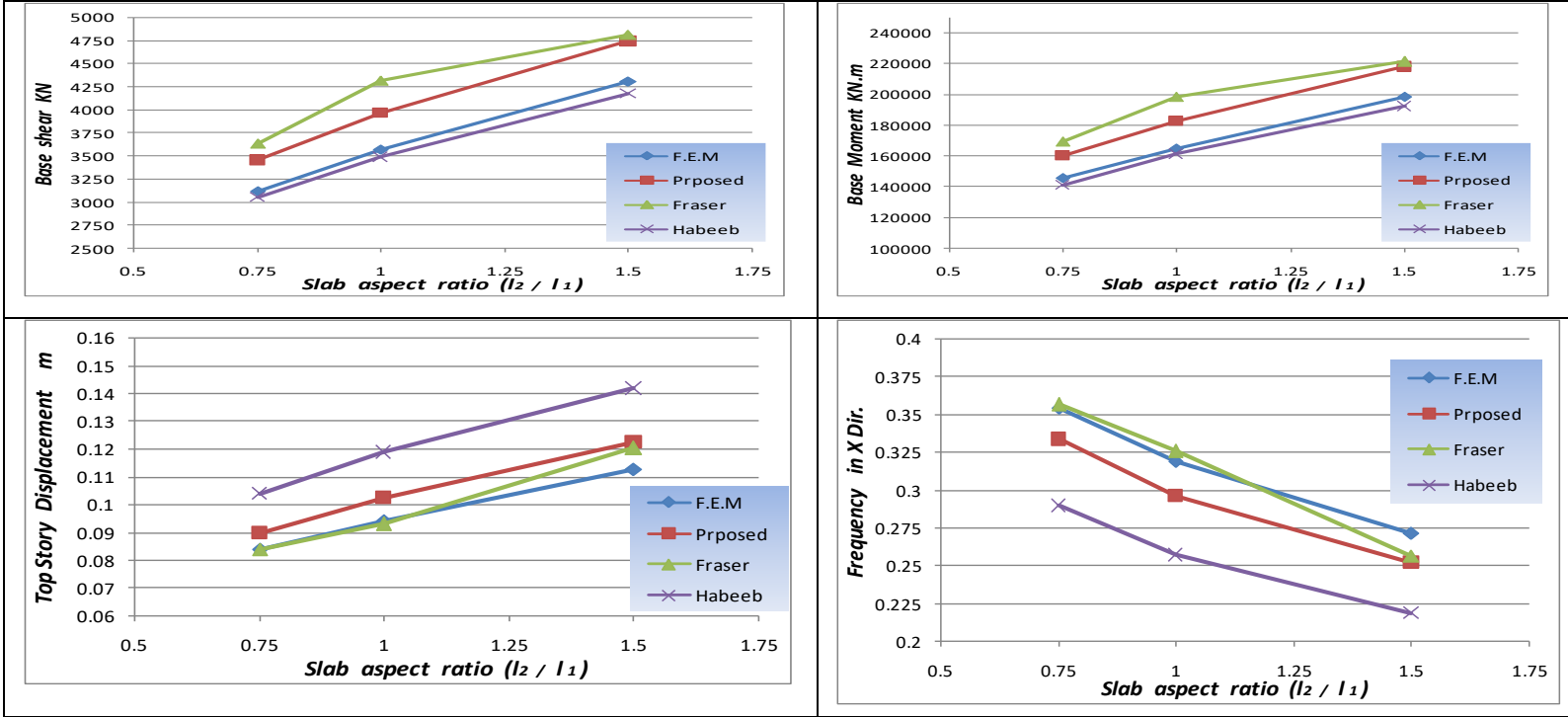

Fig. 7: Effects of Slab Aspect Ratio on Response of a 25-Story Building using Different Beams Models. 

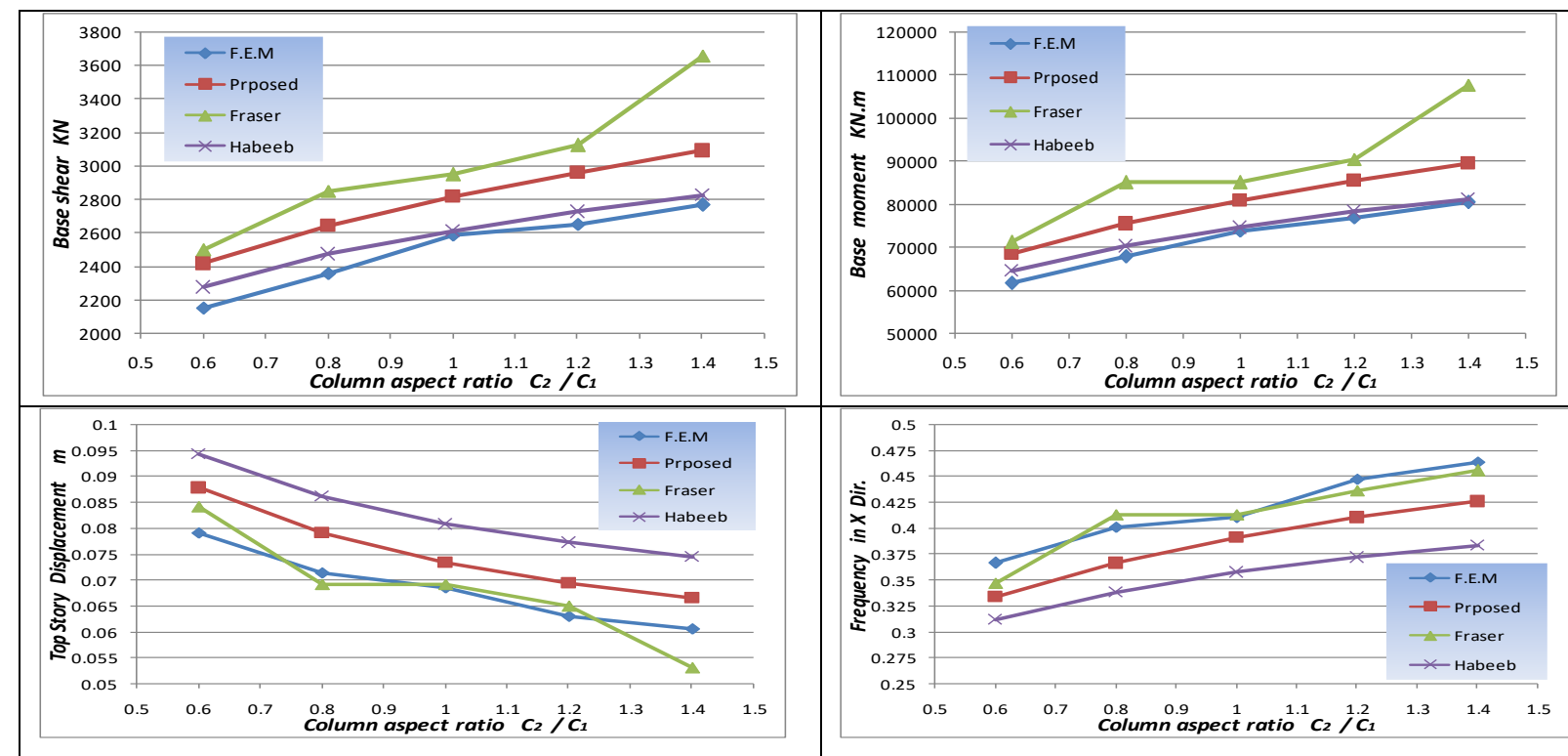

Fig. 8: Effects of Column Aspect Ratio on Response of a 15-Story Building using Different Beams Models.
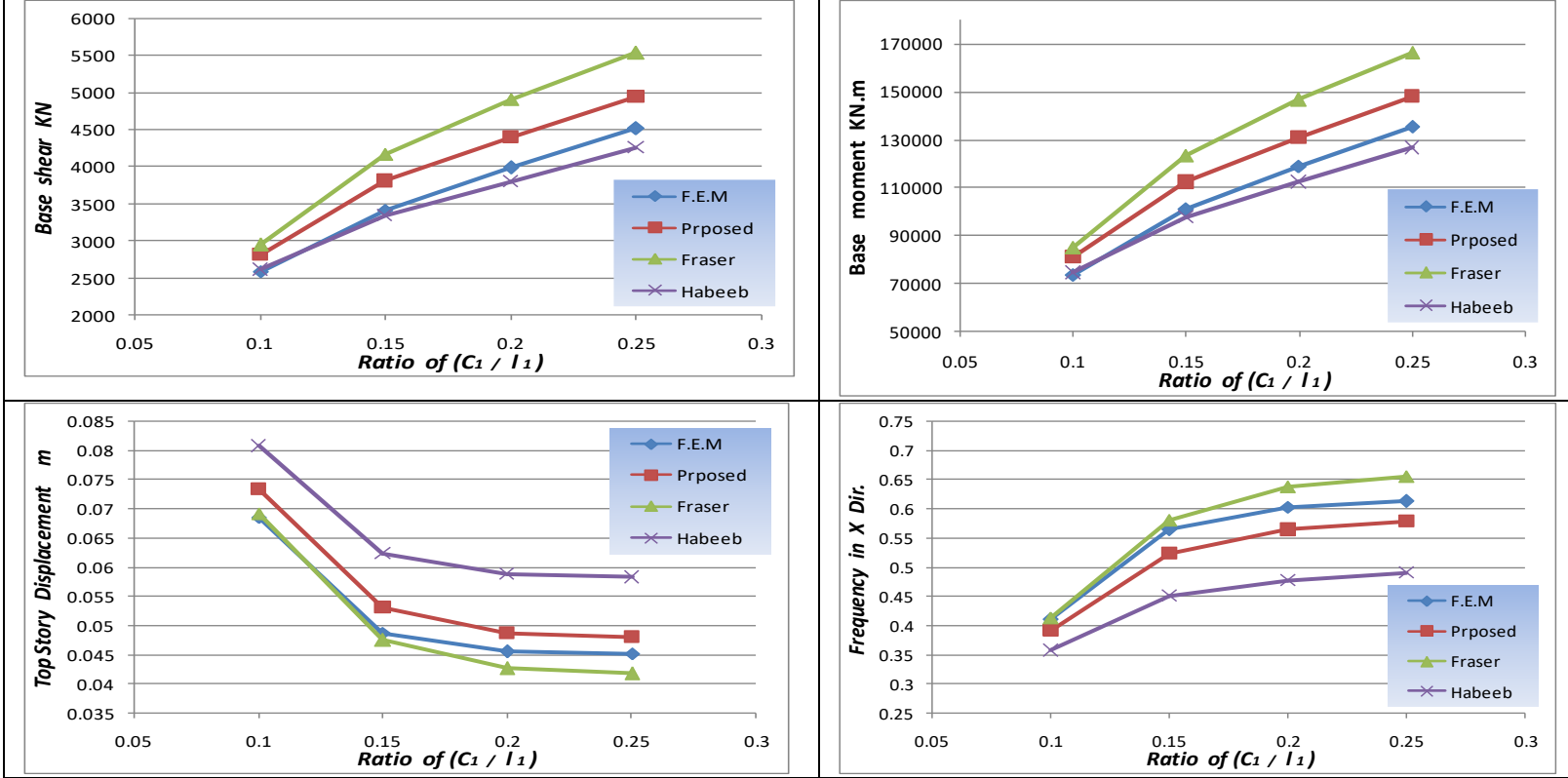

Fig. 9: Effects of Ratio $\left(\mathrm{c}_{1} / l_{1}\right)$ on Response of a 15-Story Building using Different Beams Models.
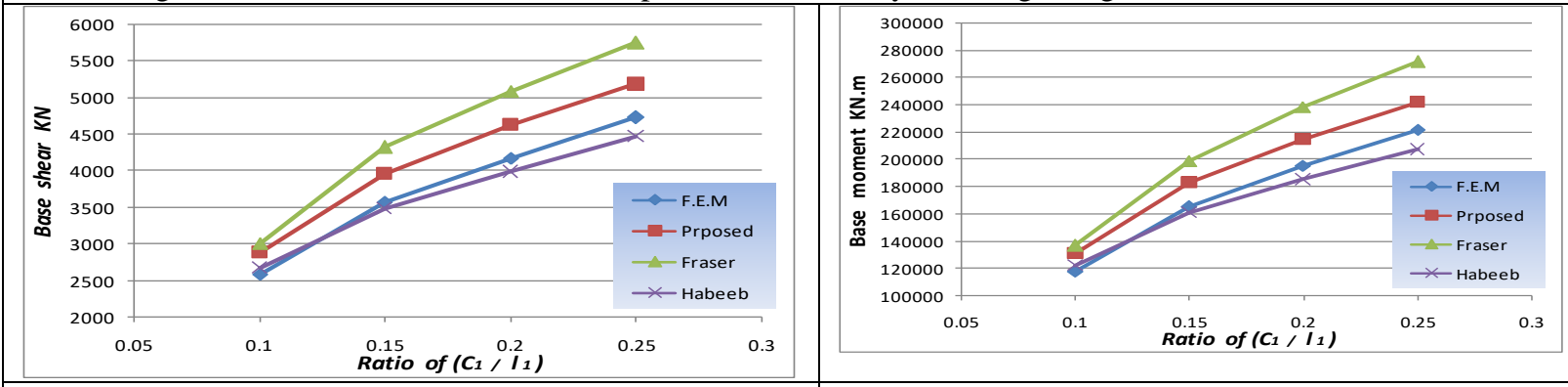

Fig. 10: Effects of Ratio $\left(\mathrm{c}_{1} / l_{1}\right)$ on Response of a 25-Story Building using Different Beams Models. 


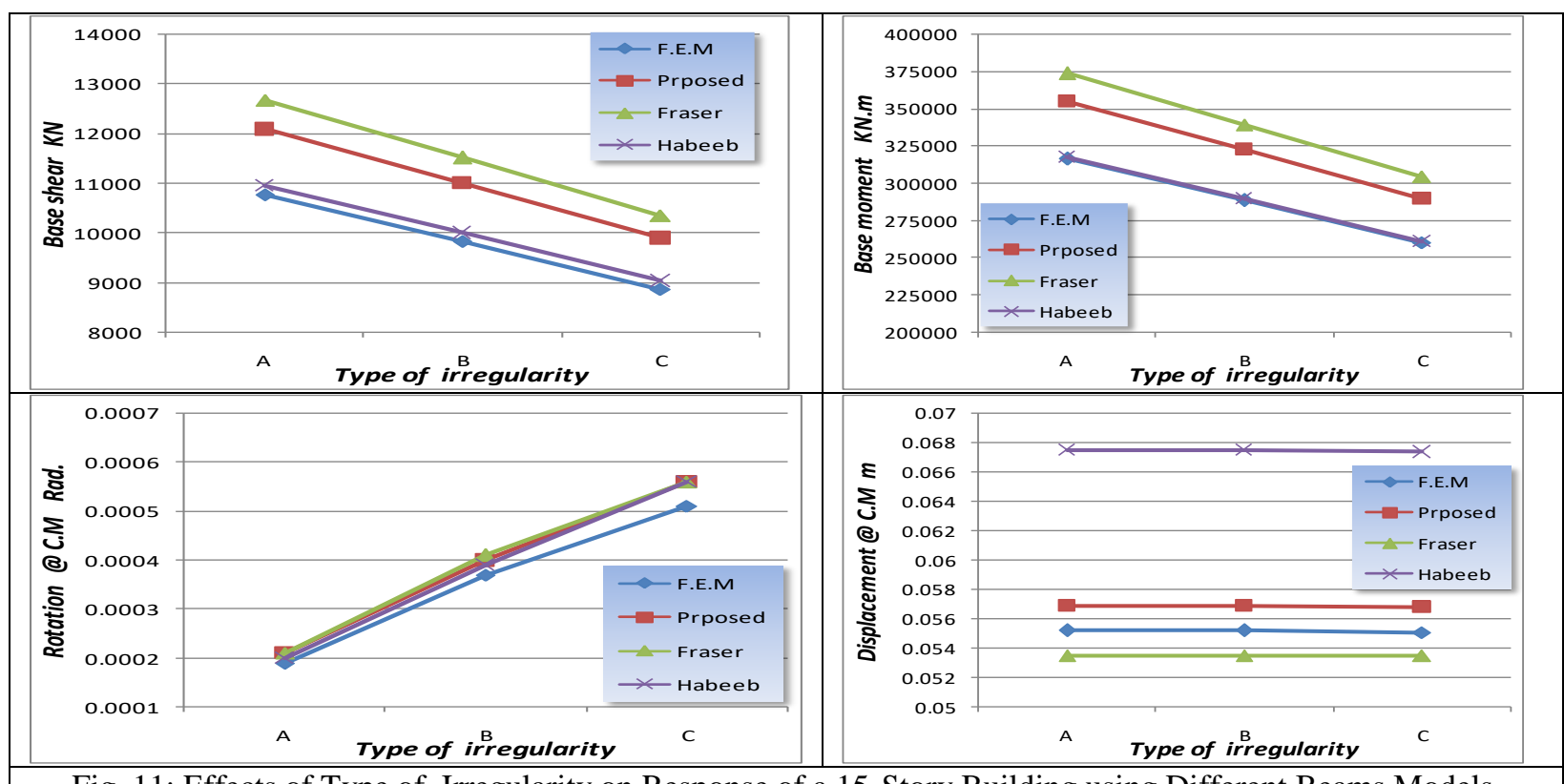

Fig. 11: Effects of Type of Irregularity on Response of a 15-Story Building using Different Beams Models.

\section{Conclusion}

1. From Figures, the following points are observed

- Fraser's model is the most appropriate model for representing high to moderate rise buildings in displacement and frequency, but this model has a large error in representing base shear and moment approximately by $17 \%$.

- Habeeb's model is the most appropriate model for representing high to moderate rise buildings in base shear and moment, but this model has a large error in representing frequency and displacement ranging from $20 \%$ to $22 \%$.

- The proposed procedure is an appropriate model for representing moderate to high rise buildings in (displacement, frequency, base shear and base moment) with acceptable differences.

2. In asymmetric structures, buildings with same height and same configuration show approximately the same rotation@ @.M whatever the type of the effective width of the slab model (all models of the effective width of the slab deviate from F.E. by a ratio ranges from $6 \%$ to $9 \%$ ). The reason behind this behavior is that the rotation of the building is a function of the column stiffness.

3. In asymmetric structures, buildings of the same height based on the same type of effective width exhibit the same displacement @ C.M whatever the plan configuration of a building is.

4. The natural frequencies of buildings under consideration based on the proposed 2D frame model were found to be underestimated by about $3 \%$ to $8 \%$ as compared to actual 3D model. These results can be justified as follows; though the mass of equivalent beams are not reduced by the proposed equivalent section model, the stiffness is underestimated clearly, thus, resulting in smaller fundamental frequencies, i.e., less energy absorbent system and hence resulting in larger displacement and smaller base shears and moments.

\section{References}

[1] F. Allen and P. Darvall, "Lateral Load Equivalent Frame," ACI Journal, No 74.32 the $14^{\text {th }}$ world Conference on Earthquake Engineering, Beijing, China, 1977.

[2] ASCE 7, "Minimum Design Loads for Buildings and Other Structures," 2010.

[3] D. J. Fraser, "Elastic Analysis of Lateral Frames" ASCE, vol. 109, no. 6, 2983, 1983.

[4] J. S. Gorossmon, "Verification of Proposed Design Methodologies for Effective with of Slab in Slab-Column Frame," ACI Structural Journal, vol. 94, no. 2, pp. 181-191, 1997. 
[5] N. Z. Habeeb, "2D Idealization Scheme to Model 3D R.C. Buildings Subjected To Earthquake," M.Sc Thesis, College of Engineering, University of Baghdad, 2007.

[6] Y. H. Luo and A. J. Darrani, "Experimental Beam Model for Flat-Slab Building, Part I, Interior Connections," ACI Structural Journal, vol. 92, no. 2, pp. 250- 257, 1995.

[7] Y. M. Park, S. W. Han, and S. H. Kee, "A modified Equivalent Method for Lateral Load Analysis," Magazine of Concrete Research, 2008.

[8] D. A. Pecknold, "Slab Width For Equivalent Frame Analysis," ACI Journal Proceeding, vol. 72, no. 4, pp. 135 $137,1975$.

[9] M. D. Vandevit, "Equivalent Frame Analysis for Lateral Load," ASEC Journal of Structural Division, vol. 105, no. ST10, pp. 1981-1997, 1979. 